\title{
GRUPO FOCAL E DISCURSO DO SUJEITO COLETIVO: PRODUÇÃO DE CONHECIMENTO EM SAÚDE DE ADOLESCENTES
}

\author{
Focal group and discourse on the collective subject: knowlegde \\ production in health of adolescents.
}

\author{
Grupos de enfoque y discurso del sujeto colectivo: produción \\ de conocimientos sobre la salud de los adolescentes.
}

\section{RESUMO}

Objetivou-se discutir o emprego do Grupo Focal (GF) para coleta e do Discurso do Sujeito Coletivo (DSC) para análise de dados em investigações no Campo da Enfermagem. Essas técnicas foram descritas sob o ponto de vista teórico e prático. Exemplificouse o emprego pelo detalhamento das etapas metodológicas, de uma pesquisa aprovada em comitê de ética, em que se buscou compreender as implicações das representações de gênero na promoção de saúde de adolescentes do ensino médio, de uma escola pública da cidade do Rio Grande, RS. 0 GF mostrou-se eficaz, desencadeando discussões e posicionamentos dos jovens acerca da temática proposta, e o DCS permitiu compreender as implicações de tais representações na promoção de saúde desse grupo. Embora tais metodologias sejam pouco utilizadas no Campo da Enfermagem, mostraram-se promissoras para a concretização de investigações científicas.

Palavras-chave: Pesquisa em Enfermagem. Saúde do Adolescente. Gênero e Saúde.

\begin{abstract}
We aimed at discussing the use of Focal Group (GF-Grupo Focal, Portuguese) for collecting and Discussing the Collective Subject (DSC-Discurso do Sujeito Coletivo, Portuguese) to analyze data in nursing field investigations. Such techniques were described through the theoretical and practical point of view. It was exemplified its use by detailing the methodological phases, in a research approved by an ethics committee, where they were studied for the implications of gender representations in promoting health of high school adolescents in a public school in Rio Grande, RS. The Focal Group proved to be efficient as it provided discussions and supported the adolescents' points of view concerning to the subject proposed, moreover, the Discussion of Collective Subject enabled a better understanding of such representations to promote health in these groups. Although these methodologies are not widely used in the nursing field, they proved to be useful in order to accomplish scientific investigations.
\end{abstract}

Keywords: Nursing Research. Adolescent. Health. Gender and health

\section{Resumen}

El objetivo del presente estudio fue discutir el uso de los Grupos de Enfoque (GE) para la recolección y del Discurso del Sujeto Colectivo (DSC) para el análisis de los datos en investigaciones en el Campo de Enfermería. Estas técnicas fueron descritas desde el punto de vista teórico y práctico. Se ejemplificó el uso del detallamiento de los pasos metodológicos, de una investigación aprobada en el Comité de Ética, que intentó comprender las implicaciones de las representaciones de género en la promoción de salud de los adolescentes de secundaria, en una escuela pública en Río Grande, RS. El GE fue eficaz, y desencadenó discusiones y posicionamientos de los(as) jóvenes, sobre el tema propuesto, y el DSC pudo entender las implicaciones de estas representaciones en la promoción de salud de este grupo. Aunque tales metodologías sean poco utilizadas en el Campo de Enfermería, fueron prometedoras para la realización de las investigaciones científicas.

Palabras-clave: Investigación en enfermería. Salud del adolescente.Género y salud.

\footnotetext{
${ }^{1}$ Enfermeira. Doutora em Enfermagem pela Universidade Federal de Santa Catarina (UFSC). Professora Titular do Departamento de Enfermagem da Fundação Universidade Federal do Rio Grande (FURG). Líder do Grupo de Estudos e Pesquisas sobre Enfermagem, Gênero e Sociedade (GEPEGS). Brasil. E-mail: vlogomes @terra.com.br.²Psicóloga. Mestre em Enfermagem pela FURG. Integrante do GEPEGS. Professora do Colégio Estadual Lemos Júnior. Brasil. E-mail: k.telles@ibest.com.br, ${ }^{3}$ Enfermeira. Aluna do Programa de Pós-Graduação em Enfermagem, curso de Mestrado em Enfermagem da FURG. Integrante do GEPEGS. Enfermeira Assistencial do Hospital Universitário São Francisco de Paula. Brasil. E-mail: evelyn.roballo@bol.com.br
} 


\section{INTRODUCÃO}

A convicção de que as profissões se solidificam pela elaboração de um corpo próprio de conhecimentos tem estimulado a produção de pesquisas no campo da Enfermagem. ${ }^{1}$ Como consequência, no cenário brasileiro, cada vez mais o cotidiano da Enfermagem vem sendo problematizado por meio da abordagem cientifica. No entanto, grande parte dos artigos publicados nos últimos anos, tanto em periódicos nacionais quanto internacionais, aponta para o predomínio de alguns recursos metodológicos, destacando-se o emprego das entrevistas semiestruturadas para a coleta de dados e da análise de conteúdo na modalidade temática como recurso analítico.

Mesmo reconhecendo o valor de tais recursos para a apreensão, compreensão ou interpretação dos objetos de estudo no campo da Enfermagem, acredita-se ser útil e oportuna a discussão de outras técnicas, com vistas a ampliar a instrumentalização para investigações científicas. Assim, o objetivo deste trabalho é discutir o emprego do Grupo Focal $(\mathrm{GF})^{2-8}$ para coleta e o do Discurso do Sujeito Coletivo (DSC) ${ }^{9-11}$ para análise de dados em investigações no Campo da Enfermagem.

Para tanto, dividiu-se este texto em três itens. No primeiro, apresenta-se a técnica de GF, salientando aspectos positivos de sua utilização junto a adolescentes. No segundo, aborda-se o DSC, como uma alternativa de análise dos dados, descrevendo suas etapas operacionais. No terceiro, exemplifica-se o emprego dessas técnicas pelo detalhamento das etapas metodológicas de uma pesquisa realizada com adolescentes.

\section{O GRUPO FOCAL: UMA ALTERNATIVA DE COLETA DE DADOS}

Pode-se definir GF como "uma técnica de coletar dados diretamente das falas de um grupo, que relata suas experiências e percepções em torno de um tema de interesse coletivo"2:258. Pode-se ainda considerá-lo uma técnica específica de coleta de dados qualitativos por meio de entrevistas grupais, caracterizada pelo uso explícito da interação grupal para a produção de dados e insights que seriam menos acessiveis fora do contexto interacional. ${ }^{3}$ Assim, o GF permite que se obtenha, para análise, um material que não surgiria em uma conversação casual, nem em resposta a perguntas previamente formuladas pelo investigador. $^{3}$

Dessa forma, o trabalho com GF permite compreender processos de construção da realidade por determinados grupos sociais, entender práticas cotidianas, ações e reações a fatos e eventos, comportamentos e atitudes. Constitui-se em importante técnica para o conhecimento das representações, percepções, crenças, hábitos, valores, restrições, preconceitos, linguagens e simbologias prevalentes no trato de uma dada questão por pessoas que partilham traços comuns e relevantes para o estudo do problema em foco. A investigação por meio de GF, além de ajudar na obtenção de perspectivas diferentes sobre uma mesma questão, torna oportuna a compreensão de ideias partilhadas por pessoas no dia-a-dia e dos modos pelos quais os indivíduos são influenciados pelos outros. ${ }^{4} \mathrm{Com}$ isso, a interação do grupo pode gerar emoção, humor, espontaneidade e intuições criativas. As pessoas nos grupos estão mais propensas a acolher novas ideias e a explorar suas implicações. Descobriuse que os grupos assumem riscos maiores e mostram uma polarização de atitudes - um movimento para posições mais extremadas. Com base nesses critérios, o grupo focal é um ambiente mais natural e holístico em que os participantes levam em consideração os pontos de vista dos outros na formulação de suas respostas e comentam suas próprias experiências e as dos outros ${ }^{5: 76}$.

Com o emprego do GF, o pesquisador "tem a oportunidade de conhecer as atitudes, comportamentos e percepções dos pesquisados 'in loco', o que reduz os custos e o tempo gastos se comparado com outras técnicas" ":395.

Do ponto de vista operacional, para estabelecer-se um número de participantes em cada grupo, deve-se considerar os objetivos da investigação, e há a sugestão de que oscile entre seis e quinze integrantes. 0 número de grupos deve ser definido em função das variáveis analisadas, sendo recomendado pelo menos dois grupos para cada uma delas ${ }^{7}$.

Em linhas gerais, os grupos devem ser compostos por um moderador, que procura promover a interação social entre os participantes, esse papel é comumente desempenhado pelo próprio pesquisador; um observador, cuja função é avaliar a condução da técnica; na falta deste elemento, o moderador a conduz integralmente. ${ }^{5} \mathrm{~A}$ escolha dos demais participantes deve ser intencional no que se refere a sexo, idade, estado civil, escolaridade, dentre outras características, ou seja, a seleção é feita de acordo com os objetivos do estudo, sendo necessário que haja no mínimo uma característica homogênea.

Para facilitar a participação e interação do grupo "os participantes e o moderador sentam num círculo, de tal modo que possa haver um contato frente-a-frente entre cada um"5:79. Após se acomodarem, "a primeira tarefa do moderador é apresentar-se a si próprio, o assunto e a ideia de uma discussão grupal"5:79.

Não há um padrão rígido para se definir o número de sessões; há casos em que uma ou duas são suficientes, há outros em que são necessárias mais sessões para que os objetivos sejam atingidos. ${ }^{7}$ No que se refere à duração de cada sessão, o preconizado é que não ultrapasse a duas horas, ${ }^{5}$ pois períodos superiores podem ocasionar cansaço e desgaste mental, prejudicando o alcance dos objetivos e dos resultados.?

0 local escolhido para a realização das sessões grupais deve ser neutro, de fácil acesso e de preferência fora do ambiente de trabalh $0^{6}$ ou da sala de aula. 0 ambiente precisa ser agradável, descontraído e sem ruídos, pois o registro dos dados deve ser efetuado por meio da gravação de voz ou imagem e complementado pelas anotações do observador. 
Grupo focal e discurso do sujeito coletivo Gomes VLO, Telles KS, Roballo EC

É inegável a importância do GF para compreender processos de construção da realidade, práticas cotidianas, ações e reações a fatos e eventos, comportamentos e atitudes, representações, percepções, crenças, hábitos, valores, restrições, preconceitos, linguagens e simbologias. ${ }^{4}$ Nesse sentido, pode-se dizer que conhecer as representações dos sujeitos sobre os mais variados objetos inerentes ao campo da saúde, da doença e do cuidado, contribui para ampliar o campo de percepções sobre as sensações, desejos e necessidades das pessoas, levando a uma prática de cuidar mais completa e complexa. ${ }^{8}$

No que se refere aos adolescentes, "durante as discussões em grupo, eles manifestam suas opiniões de forma mais autêntica, com mais veemência e menos resistências, por estarem com seus pares; logo, a identificação do grupo favorece a inter-relação" ":66. Acredita-se, assim, que a utilização do GF entre adolescentes, pela interação que proporciona, poderá incitar ao diálogo, facilitar a verbalização de dúvidas, tabus e preconceitos, além de possibilitar o compartilhamento de opiniões, emissão de inferências, busca de soluções para problemas comuns, podendo inclusive desencadear a adoção de ações promotoras de saúde.

\section{O DISCURSO DO SUJEITO COLETIVO: UMA} ALTERNATIVA DE ANÁLISE DOS DADOS

0 Discurso do Sujeito Coletivo (DSC) consiste na organização e tabulação de dados qualitativos de natureza verbal, obtidos de depoimentos, artigos de jornal, matérias de revistas semanais, papers, extraindo de cada um as ideias centrais, as ancoragens e suas correspondentes expressõeschave. ${ }^{10} E$ uma maneira de viabilizar o discurso, deixando a "realidade descrever-se mais autonomamente porque se acredita ser muito mais rico e válido ter uma realidade mais auto do que hétero descrita"10:32.

Com essa técnica, os discursos dos depoimentos não se anulam ou se reduzem a uma categoria comum unificadora já que 0 que se busca fazer é reconstruir, com pedaços de discursos individuais, como em um quebra-cabeça, tantos discursos-síntese quantos se julguem necessários para expressar um determinado modo de pensar ou representação social sobre um fenômeno. Assim, o DSC é uma estratégia metodológica que, utilizando uma estratégia discursiva, visa tornar mais clara uma dada representação social, bem como 0 conjunto das representações que conforma um imaginário específico. ${ }^{10-11}$

Para elaborar os DSCs, foram criadas as seguintes figuras metodológicas ${ }^{10-11}$ :

- Expressões-chave (ECH): são pedaços, trechos ou transcrições literais do discurso, que devem ser destacadas pelo pesquisador e que revelam a essência do depoimento ou, mais precisamente, do conteúdo discursivo dos segmentos em que ele se divide. Geralmente tais fragmentos correspondem às questões de pesquisa. "As expressões-chave são uma espécie de prova discursiva-empírica da verdade das ideias centrais e das ancoragens e vice-versa" ${ }^{10: 17}$. Com elas, são construídos os DSCS.

- Ideia central (IC): é um nome ou expressão linguística que revela e descreve, de maneira mais sintética, precisa e fidedigna possível, o sentido de cada um dos discursos analisados e de cada conjunto homogêneo de $\mathrm{ECH}$, que vai dar nascimento, posteriormente, ao DSC. É importante assinalar que a IC não é uma interpretação, mas uma descrição do sentido ou de um conjunto de depoimentos.

- Discurso do Sujeito Coletivo (DSC): é um discurso-síntese redigido na primeira pessoa do singular, a partir de trechos de discursos individuais, constituindo-se a principal dessas figuras metodológicas. Devem ser grafados em itálico para indicar que se trata de uma fala ou de um depoimento coletivo. O DSC, como técnica de processamento de dados com vistas à obtenção do pensamento coletivo, dá como resultado um painel de DSCs, justamente para sugerir uma pessoa coletiva falando como se fosse um sujeito individual de discurso. Essa forma de apresentação de resultados de pesquisa confere muita naturalidade, espontaneidade e vivacidade ao pensamento coletivo. Para elaborar o DSC, parte-se dos discursos em estado bruto, que são submetidos a uma análise inicial que os decompõe, assinalando as expressões-chave e extraindo as principais ancoragens e ideias centrais, o que culmina em uma síntese que reconstitui discursivamente a representação social.

- Ancoragem: inspirados na teoria das representações sociais, Lefèvre e Lefèvre ${ }^{10}$ adotamo termo ancoragem para se referirem a uma manifestação linguística explíita, que revela uma teoria, ideologia ou crença que alicerça as concepções do autor do discurso. A apreensão da ancoragem tem uma inegável motivação prática, principalmente em ações educativas, pois é importante explicitar as teorias, ideologias e conceitos que, muitas vezes, inconscientemente, estão subjacentes às práticas cotidianas da população ou dos profissionais.

Na construção do DSC, devem-se considerar os seguintes princípios: ${ }^{10}$

- Coerência: agregação de pedaços isolados de depoimentos para formar um todo discursivo coerente, no qual cada parte se reconheça enquanto constituinte do todo, e vice-versa.

- Posicionamento próprio: cada discurso deve expressar um posicionamento próprio, distinto, original, específico sobre o tema que está sendo pesquisado.

- Tipos de distinção entre os DSCs: quando uma resposta apresenta mais de um DSC, estes podem ser distinguidos por critérios de diferença/antagonismo ou de complementaridade. No primeiro caso, a apresentação em separado é obrigatória; no segundo, o pesquisador pode optar por uma apresentação de resultados detalhados ou mais genéricos.

- Produzindo uma "artificialidade natural": é como se uma só pessoa falasse por um grupo, traduzindo uma construção artificial. Para fazer com que o discurso coletivo pareça 
individual, devem-se 'limpar' as particularidades dos pedaços selecionados de um relato, encadeando narrativamente os discursos de forma que apresentem uma estrutura sequencial clara e coerente. "Para a construção do DSC, é preciso aproveitar todas as ideias presentes nos depoimentos para que a figura não fique incompleta" 10:21. Cabe salientar que as respostas individuais desaparecem em tal construção. Isso, em alguns estudos, pode ser considerado como um fator limitante à utilização dessa técnica analítica.

A validação dos discursos pode ser efetuada por meio de dois possíveis interpretantes. 0 primeiro, na tradição do que se chama etapa devolutiva na pesquisa qualitativa, teria como emissores os próprios informantes, aos quais seriam apresentados os DSCs construídos. 0 segundo interpretante teria como emissor o próprio pesquisador ou outro acadêmico. A função dos emissores é tecer comentários interpretativos sobre o pensamento descrito, com base no referencial teórico adotado.

\section{ETAPAS METODOLÓGICAS DE UMA PESQUISA REALIZADA COM ADOLESCENTES}

Com o objetivo de compreender as implicações de gênero na promoção de saúde de adolescentes, realizou-se uma pesquisa qualitativa, fundamentada na Teoria das Representações Sociais (RS). Essa teoria, segundo seu criador Serge Moscovici, constitui uma modalidade de conhecimento particular que circula no dia-a-dia e que tem como função a elaboração de comportamentos e a comunicação entre indivíduos. $^{12}$

Desde seu início, a pesquisa das RS tem-se caracterizado pela "utilização bastante criativa e diversificada de métodos e pelo desenvolvimento contínuo de novas técnicas, tanto no que se refere à coleta quanto ao tratamento dos dados", 13:99 o que fundamentou o emprego das técnicas do GF para a coleta, e do DSC para análise dos dados deste estudo.

0 projeto foi aprovado pelo Comitê de Ética em Pesquisa da Fundação Universidade Federal do Rio Grande, sob parecer $n^{0} 23 / 2007$.

Os dados foram colhidos nos meses de abril e maio de 2007, com onze moças e onze rapazes de 14 a 16 anos de idade, matriculados no primeiro ano do ensino médio de uma escola pública estadual da cidade do Rio Grande/RS, totalizando 22 sujeitos. Após convite, realizado em sala de aula, foram formados dois Grupos Focais, um de moças e outro de rapazes. Realizaram-se quatro sessões semanais: duas com GF feminino e duas com GF masculino. Durante essas sessões, ambos os sujeitos da pesquisa demonstraram curiosidade por conhecer as representações do outro grupo, solicitaram a realização de uma sessão mista, totalizando, com essa, cinco sessões.

A opção por grupos homogêneos, feminino e masculino, decorreu da prévia observação de que é comum, em grupos mistos, os rapazes ficarem mais quietos e terem participações menos prementes.
Cada sessão de GF contou com a participação da pesquisadora, que coordenou as atividades, de uma observadora e dos estudantes, cuja frequência oscilou entre oito e quinze. Como foram realizadas em horário oposto ao das aulas regulares, forneceu-se aos integrantes do estudo passagem de ônibus urbano e almoço.

Escolheu-se uma sala, longe da área de circulação, garantindo assim a privacidade ao longo das duas horas de realização de cada sessão. Por tratar-se de uma sala ampla, foi possível organizar as cadeiras em círculo, o que propiciou uma interação face-a-face dos participantes.

Realizaram-se a primeira e a terceira sessões com moças e a segunda e a quarta com rapazes. Inicialmente, o intuito foi apreender as representações acerca do ser mulher e ser homem em nossa sociedade. A seguir, buscou-se compreender as implicações das representações de gênero na promoção de saúde dos adolescentes. As dinâmicas propostas foram semelhantes em ambos os grupos. Na quinta sessão, realizada em grupo misto, foram apresentadas as representações de cada grupo acerca do conceito em estudo. Para tanto, houve exposição, por meio de painéis, de todo o material produzido, e os participantes tiveram a oportunidade de interagir, questionar, esclarecer, enfim problematizar o que até então fora construído.

Para apresentação dos resultados deste estudo, selecionaram-se as ECH advindas dos GFs feminino e masculino, apreenderam-se as ICs e construíram-se os DSCs, que a seguir foram discutidos.

IC: A violência contra a mulher advém de sua própria instabilidade emocional

ECHs apreendidas no grupo focal feminino:

- as mulheres são mais inteligentes e mais emocionais;

- a mulher não para de falar, falar..., aí não aguenta mais e começa a chorar, perde o controle. 0 homem não, às vezes se estressa com a mulher e dá uma "porrada" nela;

- ele chega do serviço, e a mulher começa a falar das queixas da casa, da família, isso aquilo... Aí ele vai lá e senta a "porrada" nela. Ele não tem paciência para conversar e resolver os problemas;

- o homem quando bate, às vezes, porque está estressado, não chega ser um descontrole;

- tem mulher que gosta de apanhar;

- tem mulher que bate, mas é difícil ver um homem chorar quando está com raiva.

DSC:

As mulheres são mais inteligentes e mais emocionais que os homens. Elas perdem o controle com facilidade e começam a chorar. A mulher estressa o marido ao compartilhar com ele os assuntos da casa. Ele, por não ter paciência para conversar e resolver os problemas, pode bater nela. Às vezes o homem bate porque está estressado, mas não chega a ser um descontrole. Tem mulher que gosta de apanhar e tem mulher que bate. Ver um homem chorar, quando está com raiva, é difícil. 
Grupo focal e discurso do sujeito coletivo Gomes VLO, Telles KS, Roballo EC

Evidencia-se, nesse discurso que, embora as adolescentes considerem o choro como um descontrole feminino, não percebem os atos de violência do homem como uma forma de descontrole, avaliam que geralmente eles têm motivos para agir violentamente. Isto se ancora na ideia de que o espaço privado é assunto para a mulher, cabendo-lhe resolver todas as situações a ele relacionadas. Por outro lado, mesmo o homem não tendo ingerência no espaço privado, pode exercer seu poder e domínio sobre a mulher, estando naturalmente autorizado a agir com violência quando ela não cumpre com suas obrigações.

Assim, é considerada fundamental a incorporação das questões de gênero no problema da violência contra mulher, pois é por meio de situações cotidianas e repetitivas que 0 papel feminino vai sendo definido. Ao destinar para a mulher um papel submisso e passivo, a sociedade cria espaço para a dominação masculina, no qual o processo de mutilação feminina é lento, gradual e considerado legítimo. ${ }^{14}$ Tal consideração é constatada no discurso das adolescentes, que atribuem, muitas vezes, à própria mulher a responsabilidade pela agressão da qual foi vítima; assim, passam a ideia de que, em certas situações, o homem está no seu direito de bater. Entretanto, mesmo não havendo relatos de sofrimento de violência pelas adolescentes do estudo, ao legitimarem a violência masculina como uma forma de expressão do estresse masculino, mostramse mais vulneráveis a situações dessa natureza até mesmo durante o período de namoro.

Os efeitos negativos da violência não se fazem sentir apenas na saúde física e mental da mulher, mas também na sociedade como um todo, na medida em que os efeitos físicos e psicológicos do abuso influenciam a capacidade e produtividade das mulheres. ${ }^{15}$

Dessa forma, é necessário que os profissionais da saúde tenham o entendimento das implicações de gênero na violência contra a mulher. É até frequente a culpabilização da vítima, mas se torna necessária a compreensão do contexto e da dinâmica que se opera no relacionamento, a qual desencadeia o sentimento de impotência da mulher diante da violência. Esse olhar permite a aproximação do profissional com a vítima, possibilitando o resgate de sua autoestima, a reflexão sobre sua postura e a visualização de novas alternativas de vida que não sejam baseadas na sujeição.

IC: Virilidade e masculinidade são atributos que precisam ser comprovados na adolescência

ECHs apreendidas no grupo focal masculino:

- às vezes o filho cresce com aquela pressão: "o meu filho vai ser macho, garanhão", depois vira gay ou outra coisa. Há preconceito;

- o filho ser gay, pode ser provar do próprio veneno, porque botaram muita pressão em cima;

- por exemplo, o pai fala: "o meu filho tem o tico grande", aí quando cresce não tem, é normal. 0 cara pode se sentir mal;

- às vezes se espera coisas que não dependem da vontade do filho;
Esc Anna Nery Rev Enferm 2009 out-dez; 13 (4): 856-62

- a saúde dos adolescentes é mais frágil que dos adultos, pois os adultos se abrem uns para os outros. Conversam mais uns com os outros, mostram o que estão sentindo;

- os adultos já têm mais experiência de vida. Eles têm mais amizade uns com os outros. Dependendo, se for casado ou algo assim, ele tem a pessoa ao seu lado que pode conversar;

- às vezes tu precisa ter alguém para trocar uma ideia junto contigo.

DSC:

Às vezes o filho cresce sobre a pressão de ser macho e garanhão, se isso não acontecer e ele for homossexual, haverá preconceito. Isso para o pai seria como provar do próprio veneno, um castigo pela pressão exercida. Pais esperam do filho coisas que não dependem da vontade dele, como, por exemplo, ter o pênis grande; o simples fato de ter, na idade adulta, o pênis com o tamanho normal, pode fazer o homem sentir-se mal. A saúde dos adolescentes é mais frágil que a dos adultos. Estes têm mais experiência de vida, mais amizades, compartilham os sentimentos, conseguem mostrar o que sentem. Ter um(a) companheiro(a), possibilita o diálogo, pois, às vezes, precisa-se ter alguém para trocar ideias.

É perceptível, no discurso dos adolescentes, que a pressão exercida pela sociedade, e principalmente pelo pai, para tornarem-se machos, garanhões é intensa. Ter que atender todas as expectativas não é uma tarefa fácil. Também há questões referentes à anatomia do corpo do homem que são valorizadas como prova de masculinidade, ou seja, na representação circundante de que quanto maior o tamanho do pênis mais macho será o homem. A sensação de ter um pênis pequeno compromete a autoestima e a autoimagem e influi significativamente no comportamento masculino. Culturalmente, relacionam-se as dimensões do pênis com a capacidade não só erétil, mas de dar prazer à parceira. Assim, muitos homens, especialmente os jovens, têm medo de não serem considerados normais pelas mulheres. Há ainda a pressão dos pais que, movidos pela ansiedade e comparando seus filhos com os outros meninos, podem deixar sequelas psicológicas importantes. As exigências para com o filho podem trazer implicações para a saúde em vários aspectos. Tendo que cumprir o papel de garanhões, há pressão social para somarem o maior número possível de conquistas sexuais, além disso, não devem demonstrar inseguranças e dúvidas acerca de sua vida sexual, o que os torna mais vulneráveis às DSTs e AIDS.

A busca pelos serviços de saúde é distinta entre adolescentes dos sexos feminino e masculino, pois há o reflexo das construções socioculturais e das desigualdades de gênero. Os rapazes pouco utilizam os serviços de saúde com o objetivo de cuidar da saúde sexual e reprodutiva, havendo pouca procura para atendimento em planejamento familiar. ${ }^{16}$ 
O homem que não consegue atender ou satisfazer todos os predicados da masculinidade ideal sofre terrivelmente, chegando a pagar com a própria saúde e, em alguns casos, com a vida, para demonstrar sua macheza. Não é tarefa fácil para ele ter garantida sua posição de poder, tradicionalmente concebido. Sentir-se fraco, ficar doente, ser traído pela mulher, perder o emprego, ser estéril ou impotente, não são simplesmente situações desagradáveis, mas sinais que podem ameaçar o referencial de virilidade. ${ }^{17}$

Nesse sentido, pode-se considerar que a pressão, exercida sobre os adolescentes, faz com que eles percebam sua saúde mais frágil que a dos adultos. Ao expressarem que estes têm mais experiência de vida, talvez estejam querendo dizer que veem os adultos como pessoas que superaram o sofrimento emocional da pressão social, atribuindo a essa superação a importância de terem alguém para compartilhar sentimentos e ideias.

Observa-se, nesses elementos do discurso, que os adolescentes necessitam projetar uma vida adulta com amizades e com um relacionamento estável. Essa necessidade parece uma incoerência, pois o adolescente vive cercado de amigos e a comunicação nos dias de hoje é facilitada pela Internet, mas isso não Ihes é suficiente. 0 adolescente sentese solitário, o que pode demarcar fragilidades no seu desenvolvimento emocional e social, pois sentimentos de insegurança, dúvidas e anseios permanecem reprimidos.

\section{CONSIDERAÇÕES FINAIS}

Com esse relato, procurou-se apontar para a necessidade de diversificação de referenciais metodológicos em função da população investigada e dos objetivos propostos. Pela adoção de metodologias que propiciem a interação, é possível que investigador e investigados compartilhem ideias e busquem soluções para seus problemas por meio do diálogo, podendo, inclusive, proporcionar o desenvolvimento de ações promotoras de saúde.

O GF mostrou-se uma técnica eficaz para a coleta de dados, pois favoreceu aos adolescentes expressarem suas representações de gênero por meio das reflexões, discussões e posicionamentos, da mesma forma que a análise por meio do DCS permitiu a compreensão das implicações de tais representações na promoção de saúde desse grupo etário. Por outro lado, a problematização, acerca do foco do estudo, possibilitou que as representações dos adolescentes fossem em alguns casos reforçadas, em outros reformuladas, ou mesmo substituídas. Assim, novas modalidades de cuidado e de autocuidado puderam ser vislumbradas, e foi possível desencadear reflexões sobre educação em saúde.

É de grande relevância que o cuidado a adolescentes esteja embasado em seu cotidiano, ou seja, que as representações sociais, que permeiam seu dia-a-dia, sejam do conhecimento dos profissionais que se dedicam à prestação desse cuidado.
Nesse sentido, as técnicas do GF e do DSC possibilitaram tanto essa apreensão quanto sua compreensão, pois o DSC, ao adquirir a forma de um painel de discursos, reflete o que se pode pensar, em uma dada formação sociocultural, em uma dada coletividade, sobre um determinado assunto. ${ }^{10-11}$

Assim, embora tais metodologias sejam pouco utilizadas no campo da enfermagem, mostram-se promissoras para a concretização de investigações científicas, devendo ser divulgadas tanto na teoria quanto na prática.

\section{REFERÊNCIAS}

1 Gomes VLO, Backes VMS, Padilha MICS, Vaz MRC. Evolução do conhecimento científico na enfermagem: do cuidado popular à construção de teorias. Invest Educ Enferm 2007 set; 25 (2): 10915.

2 Leopardi MT, Beck CLC, Nietsche EA, Gonzales RMB. Metodologia da pesquisa na saúde. Santa Maria (RS): Pallotti; 2001.

3 Banchs MA. Representaciones sociales en proceso: su análisis a través de grupos focales. In: Moreira ASP, Camargo BV, Jesuíno JC, Nóbrega SM, organizadores. Perspectivas teórico-metodológicas em representações sociais. João Pessoa (PB): UFPB Universitária; 2005. p.401-23.

4 Gatti BA. Grupo focal na pesquisa em ciências sociais e humanas. Brasília (DF): Líber Livro; 2005.

5 Gaskell G. Entrevistas individuais e grupais. In: Bauer MW, Gaskell G. Pesquisa qualitativa com texto, imagem e som: um manual prático. $4^{\text {a }}$ ed. Petrópolis (RJ): Vozes; 2005. p. 72-88.

6 Meier MJ, Kudlowiez S. Grupo focal: uma experiência singular. Texto\&Contexto Enferm 2003 jul/set; 12 (3): 394-99.

7 Westphal MF, Bógus CM, Faria MM. Grupos focais: experiências precursoras em programas educativos em saúde no Brasil. Bol Of Sanit Panam 1996; 120 (6): 472-81.

8 Ferreira MA. A educação em saúde na adolescência: grupos de discussão como estratégia de pesquisa e cuidado-educação. Texto\&Contexto Enferm2006 abr/jun; 15 (2): 205-11.

9 Telles KS. Representações de adolescentes acerca de sexualidade, gênero e as implicações na promoção de saúde [dissertação de mestrado]. Rio Grande (RS):Fundação Universidade Federal do Rio Grande/ FURG; 2007.

10 Lefèvre F, Lefèvre AMC. 0 discurso do sujeito coletivo: um novo enfoque em pesquisa qualitativa (desdobramentos). Caxias do Sul ( RS): Educs; 2005.

11 Lefèvre F, Lefèvre AMC. Discurso do sujeito coletivo, complexidade e auto organização. Rev Ciencia Saude Colet (no prelo). [citado 6 maio 2007] Disponível em:

http://www.abrasco.org.br/cienciaesaudecoletiva/artigos/ artigo_int.php?id_artigo $=622$.

12 Moscovici S. A representação social da psicanálise. Tradução de Álvaro Cabral. Rio de Janeiro (RJ): Zahar; 1978.

13 Sá CP. Núcleo central das representações sociais. Petrópolis(DF): Vozes; 2002.

14 Soares SM, Amaral MA, Silva LB, Silva PAB. Oficinas sobre sexualidade na adolescência: revelando vozes, desvelando olhares de estudantes 
Grupo focal e discurso do sujeito coletivo Gomes VLO, Telles KS, Roballo EC

Esc Anna Nery Rev Enferm 2009 out-dez; 13 (4): 856-62

do ensino médio. Esc Anna Nery Rev Enferm 2008 set; 12(3): 48591.

15 Pitanguy J. Violência de gênero e saúde-interseções. In: Berquó ES. Sexodvida: panorama da saúde reprodutiva no Brasil. Campinas (SP): UNICAMP; 2003.
16 Ministério da Saúde (BR). Informações em saúde. 2006 [on-line] [citado 29 set 2007]. Disponível em: http://www.saúde.gov.br

17 Paschoalik RC, Lacera MR, Centa ML. Gênero masculino e saúde. Cogitare Enferm 2006 jan/abr; 11 (1): 80-3. 